\title{
Influence of Sodium Nitrite on the Early Strength of Cement-Fly Ash Composite Cementitious Material
}

\author{
LIU Runqing ${ }^{1,}$, , WANG Yufei ${ }^{2, b}$ and SHENG Guodong ${ }^{3, c}$
}

${ }^{1}$ School of materials science and engineering, Shenyang Ligong University, Shenyang, China

${ }^{2}$ School of materials science and engineering, Shenyang Jianzhu University, Shenyang, China

${ }^{3}$ Liaoning rail transportation career Academy, Shenyang, China

a13940195514@163.com, baquarius1990@163.com, ${ }^{\mathrm{c}} 775773808 @ q q . c o m$

\begin{abstract}
Keywords: Anti-freezing agent, low-temperature concrete, sodium nitrite, early strength
Abstract. Corresponding to the conventional anti-freezing agent, namely, sodium nitrite, the early strength development of the cement-fly ash composite cementitious material curing in the solution of water and sodium nitrite were investigated, respectively. The results show that, adding sodium nitrite increases the volume of sulphoaluminate in the composite cementitious material at the early stage, which lowers the strength of the composite cementitious material that curing at $5^{\circ} \mathrm{C}$. The addition of fly ash could contribute to the improvement of the later strength of the composite cementitious material that curing at $5^{\circ} \mathrm{C}$.
\end{abstract}

\section{Introduction}

The main external factors that lead to frost-damage of low-temperature concrete are the effect of temperature and water morphology in winter construction[1-5]. In order to ensure the quality and safety of concrete construction in winter, the construction process as well as the material composition has been studied by experts in various countries and has acquired some achievements[6,7], and aimed at the effect of temperature and moisture on traditional concrete a typical common measure was proposed that adding a certain amount of antifreeze agent in the process of concrete stirring[8]. According to Arrhenius principle, the moisture of the concrete cannot be frozen at negative temperature and can maintain a certain activity, which ensures to continue the hydration hardening of the concrete and to produce strength even at low temperatures. With the complexity of the composition of materials and the application of fly ash in low temperature concrete, whether the use of traditional antifreeze agent is suitable for current low-temperature concrete technology needs to be studied. In this paper, aimed at cement-fly ash composite cementitious material, the early strength development of the composite material in sodium nitrite aqueous solution was investigated.

\section{Experiments}

Materials. The Portland cement (P• II 52.5R)was supplied by Dalian Xiaoyetian cement plant, of which the specific surface is $380 \mathrm{~m}^{2} / \mathrm{kg}$. The main chemical composition is given in Table 1 .

The fly ash (Grade I )was provided by Shenyang Shenhai thermal power plant, of which $\mathrm{SiO} 2>50 \%, \mathrm{CaO}<5 \%$ and loss on ignition is less than $5 \%$. The fly ash is classified as Class $\mathrm{F}$ fly ash and is in line with the requirements of "Used in cement and concrete and fly ash" (GB/T1596-2005). The main composition is presented in Table 2.

Tap water was used and the early strength agent and anti freezing agent were sodium nitrite, which are in line with the technical conditions GB/T633-1994.

Table 1 Chemical composition of Portland cement $(\omega / \%)$

\begin{tabular}{llllllll}
\hline $\mathrm{CaO}$ & $\mathrm{SiO}_{2}$ & $\mathrm{Al}_{2} \mathrm{O}_{3}$ & $\mathrm{Fe}_{2} \mathrm{O}_{3}$ & $\mathrm{MgO}$ & $\mathrm{SO}_{3}$ & Other & Loss \\
\hline 65.3 & 21.3 & 4.85 & 3.38 & 1.53 & 2.0 & 1.54 & 1.63 \\
\hline
\end{tabular}


Table 2 Chemical composition of fly ash $(\omega / \%)$

\begin{tabular}{llllllll}
\hline $\mathrm{SiO}_{2}$ & $\mathrm{Al}_{2} \mathrm{O}_{3}$ & $\mathrm{Fe}_{2} \mathrm{O}_{3}$ & $\mathrm{CaO}$ & $\mathrm{MgO}$ & $\mathrm{Na}_{2} \mathrm{O}$ & $\mathrm{K}_{2} \mathrm{O}$ & Loss \\
\hline 59.9 & 26.78 & 4.35 & 2.30 & 1.53 & 1.25 & 2.75 & 1.29 \\
\hline
\end{tabular}

Experimental proportions. Based on the state and working property of the composite cementitious material mortar which were obtained by the previous test, the water to cement ratio of the mortar and cement paste were set as 0.42 . Specimens were cured at temperature of $5^{\circ} \mathrm{C}$, water to cement ratio was fixed, and specimens added with $10 \%, 20 \%$ and $30 \%$ of fly ash were compared to that without fly ash. The specimens size are $40 \mathrm{~mm} \times 40 \mathrm{~mm} \times 160 \mathrm{~mm}$. The mix proportion of composite binding materal cement paste at low temperature is presented in Table 3.

Table 3 The mix proportion of composite binding material cement paste at low temperature

\begin{tabular}{cccccc}
\hline \multirow{2}{*}{ NO. } & \multicolumn{5}{c}{ Dosages of paste specimen in each group } \\
\cline { 2 - 6 } & $\mathrm{T} /{ }^{\circ} \mathrm{C}$ & Cement/g & Fly ash/g & Water/g & Sodium nitrite/g \\
\hline $\mathrm{A}$ & $5^{\circ} \mathrm{C}$ & 450 & 0 & 189 & 0 \\
$\mathrm{~A} 1$ & $5^{\circ} \mathrm{C}$ & 405 & 45 & 189 & 0 \\
$\mathrm{~A} 2$ & $5^{\circ} \mathrm{C}$ & 360 & 90 & 189 & 0 \\
$\mathrm{~A} 3$ & $5^{\circ} \mathrm{C}$ & 315 & 135 & 189 & 0 \\
$\mathrm{~B}$ & $5^{\circ} \mathrm{C}$ & 450 & 0 & 189 & 38.25 \\
$\mathrm{~B} 1$ & $5^{\circ} \mathrm{C}$ & 405 & 45 & 189 & 38.25 \\
$\mathrm{~B} 2$ & $5^{\circ} \mathrm{C}$ & 360 & 90 & 189 & 38.25 \\
$\mathrm{~B} 3$ & $5^{\circ} \mathrm{C}$ & 315 & 135 & 189 & 38.25 \\
\hline
\end{tabular}

Table 4 The Flexural strength and compressive strength of composite binding material cement mortar(mixed with 0 , $10 \%, 20 \%$ and $30 \% \mathrm{FA})$ in different hydration environment curing at $5^{\circ} \mathrm{C}$

\begin{tabular}{|c|c|c|c|c|c|c|c|}
\hline \multirow{2}{*}{ NO. } & \multirow{2}{*}{ Mix ratio } & \multirow{2}{*}{$\mathrm{T} /{ }^{\circ} \mathrm{C}$} & \multirow{2}{*}{ Environment } & \multicolumn{4}{|c|}{ Strength /MPa } \\
\hline & & & & & $3 \mathrm{~d}$ & $7 \mathrm{~d}$ & $14 \mathrm{~d}$ \\
\hline $\mathrm{A}$ & Cement & 5 & \multirow{4}{*}{ Water } & \multirow{8}{*}{ Flexural strength } & 8.9 & 9.4 & 9.5 \\
\hline A1 & FA $10 \%$ & 5 & & & 8.4 & 9.1 & 9.2 \\
\hline $\mathrm{A} 2$ & FA20\% & 5 & & & 6.7 & 8.5 & 8.9 \\
\hline A3 & FA30\% & 5 & & & 5.8 & 7.8 & 8.2 \\
\hline $\mathrm{B}$ & Cement & 5 & \multirow{4}{*}{ Sodium nitrite } & & 7.4 & 9 & 9.8 \\
\hline $\mathrm{B} 1$ & FA10\% & 5 & & & 7.2 & 8.7 & 9.4 \\
\hline $\mathrm{B} 2$ & FA $20 \%$ & 5 & & & 6.1 & 8.4 & 9.1 \\
\hline B3 & FA30\% & 5 & & & 6 & 7.7 & 8.5 \\
\hline A & Cement & 5 & \multirow{4}{*}{ Water } & \multirow{8}{*}{ Compressive strength } & 35.9 & 42.3 & 44.8 \\
\hline A1 & FA10\% & 5 & & & 27.9 & 39.9 & 44 \\
\hline $\mathrm{A} 2$ & FA20\% & 5 & & & 24.1 & 35.5 & 43.7 \\
\hline A3 & FA30\% & 5 & & & 19 & 31.5 & 39.4 \\
\hline $\mathrm{B}$ & Cement & 5 & \multirow{4}{*}{ Sodium nitrite } & & 23.5 & 34 & 36.4 \\
\hline B1 & FA10\% & 5 & & & 23.2 & 31.7 & 35.9 \\
\hline $\mathrm{B} 2$ & FA20\% & 5 & & & 19.8 & 28 & 30.9 \\
\hline B3 & FA30\% & 5 & & & 18.8 & 26.2 & 27.7 \\
\hline
\end{tabular}

\section{Results and discussions}

The flexural and compressive strength of the composite cementitious material mortar specimens added with different additions of fly ash $(0,10 \%, 20 \%$ and $30 \%)$ were tested according to Cement Mortar Strength Test Method (ISO), which were cured for $3 \mathrm{~d}, 7 \mathrm{~d}$ and $14 \mathrm{~d}$ in different hydration aqueous solution at temperature of $5^{\circ} \mathrm{C}$. The data is presented in Table 4 . 
The flexural and compressive strength curves are given in Fig.1 and Fig.2 which are drawn according to the data in Table 4 . The tested specimens were cured for $3 \mathrm{~d}, 7 \mathrm{~d}$ and $14 \mathrm{~d}$ in different aqueous solution at temperature of $5^{\circ} \mathrm{C}$.

The flexural strength data of the mortar specimens, which were cured under the same maintenance system for a certain stage in complex hydration solution of tap water and sodium nitrite respectively, is given in Fig.1. Except for individual circumstances, Fig.2 illustrates that the flexural strength of the cementitious material mortar specimens curing for 3days and 7 days in water environment exceed the ones in the complex solution environment. However, the flexural strength of the specimens curing for 14 days in the complex solution environment are higher than that (same proportion) in water environment. Compared to the specimens curing for 14 days in water solution environment, the flexural strength of the specimens (same proportion and curing age) curing in sodium nitrite solution environment increased by $3.1 \%, 2.1 \%, 2.2 \%$ and $3.5 \%$, respectively. It illustrates that the influence of adding sodium nitrite on the flexural strength growth of the cementitious material specimens curing for less than 7 days is weak but can increase the flexural strength of which curing for more than 7 days. In addition, it can be seen from the flexural strength data that, the effect of adding sodium nitrite on the flexural strength of the cementitious material mortar specimens, which incorporated high volume of fly ash or without fly ash, is obvious.

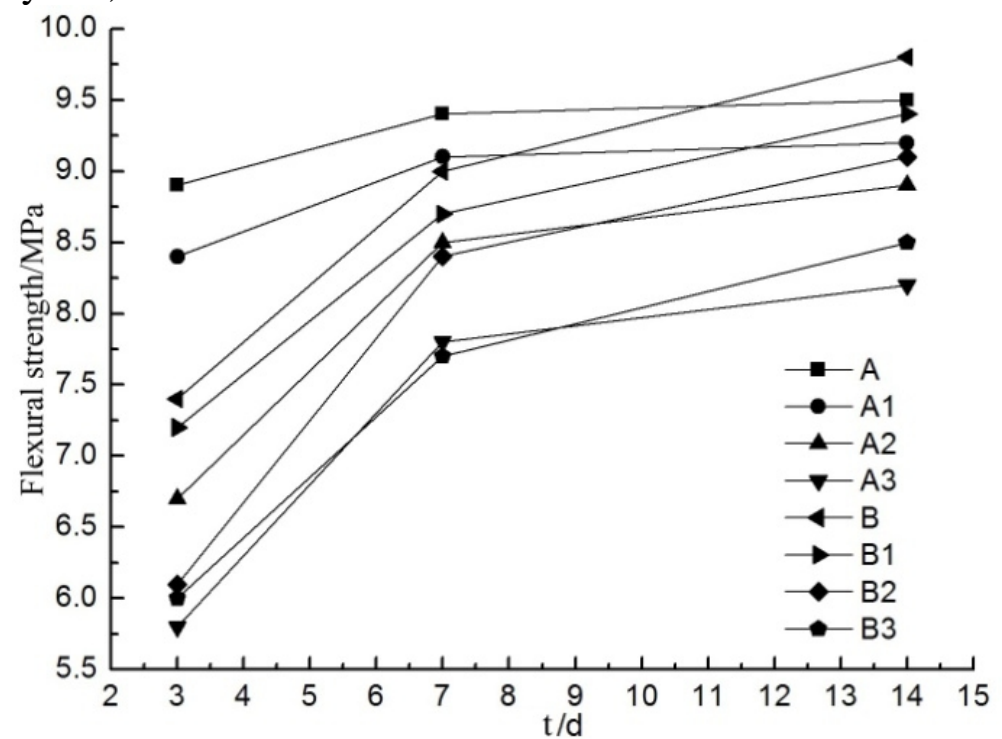

Figure 1. The bending strength of cement mortars(mixed with 0,10\%, 20\% and 30\% FA) in different hydration environment curing at $5^{\circ} \mathrm{C}$

Fig.1 illustrates that, the flexural strength of the mortar specimens (curing at $5{ }^{\circ} \mathrm{C}$ ) incorporated with $10 \%$ of fly ash or without fly ash has strength advantage over that incorporated with more than $10 \%$ of fly ash. In addition, the mortar specimens added with $10 \%$ of fly ash or without fly ash and curing in water solution hydrated rapidly and at the age of $7 \mathrm{~d}$ it was close to complete the hydration. However, the early hydration rate of the specimens curing in sodium nitrite solution was delayed. At the age of $3 \mathrm{~d}$, the flexural strength of the specimens was far below that curing in water solution environment, while, its flexural strength grew rapidly at the late age. At the age of $7 \mathrm{~d}$ the strength was close, and at the age of $14 \mathrm{~d}$ its flexural strength exceeded the specimens curing in water solution.

Corresponding to the above phenomenon, adding sodium nitrite decreases the amount of water that contacts with the cementitious material and to cause the lower flexural strength of the mortar specimens curing in sodium nitrite aqueous solution compared to that curing in water solution at the early stage. Moreover, the curing environment for the experiment was provided by refrigerator of which the inside room was narrow and sealed, while, the water to cement ratio 0.42 was the minimum one for that curing under sealed environment. With the continuing of the hydration, the amount of water needed for the specimens was insufficient, which hindered the hydration reaction of the cementitious material and lowered the flexural strength growth rate of the specimens curing for more than 7 days. However, with regard to the mortar specimens curing in sodium nitrite aqueous solution, 
the sodium nitrite dissolved in the water precipitated with the decrease of the amount of water after the solution reaching saturation. And the precipitated sodium nitrite can easily absorb the surrounding moisture and deliquesced, which provided moisture for the hydration of the cementitious material and the hydration can also react slowly. The hydration products are extended in the pores of the cement mortar. The voids in the specimens of the cementitious materials are further filled, which increases the flexural strength of the hydrated mortar specimens curing in the sodium nitrite aqueous solution environment.

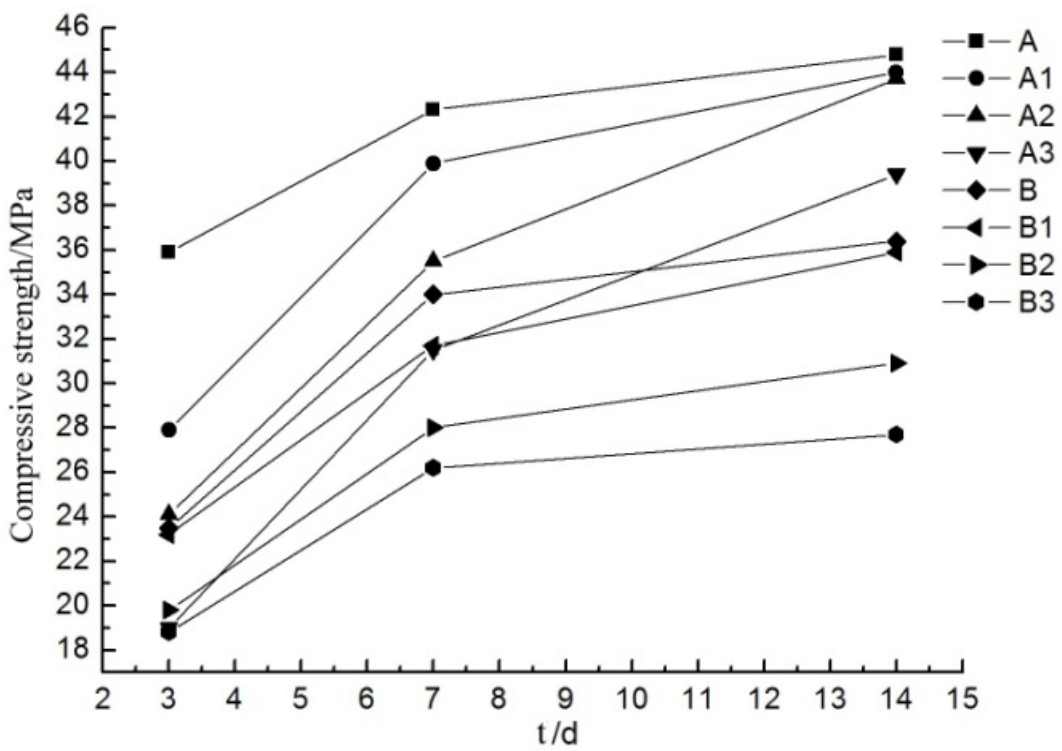

Figure 2. The compressive strength of cement mortars(mixed with $0,10 \%, 20 \%$ and $30 \% \mathrm{FA}$ ) in different hydration environment curing at $5^{\circ} \mathrm{C}$

Fig.2 illustrates the compressive strength data of the mortar hydrated in the solution of water and sodium nitrite under the same curing system. As is presented in the graph that the order and trend of the curves of the compressive strength of the mortar specimens (curing at $5^{\circ} \mathrm{C}$ ) hydrated in different hydration solution have obvious differences with the flexural strength curves.

With regard to the mortar specimens curing for less than 7 days, the compressive strength of the mortar specimens curing in solution of water were higher than that curing in solution of sodium nitrite except for the specimens incorporated $30 \%$ of fly ash, while, the compressive strength of the specimens added with $30 \%$ of fly ash increased rapidly after curing for 7 days. And at the stage of 14d, although there was still a large gap compared to the specimens (the other proportions) curing in the solution of water, its compressive strength was higher than that (with any other proportion)curing in the solution of sodium nitrite. In addition, the trend of the curves illustrate that the increasing trend of the compressive strength of the mortar specimens curing for more than 7 days in the solution of sodium nitrite tends to slow down, which is contrary to the increasing trend of the flexural strength at the later stage in Fig.1.

With regard to the above phenomenon, on the one hand, it is caused by the differences of the morphology of the hydration products, the morphology of hydration products affected the microstructure of cementitious materials to a great extent and further to affect the macro strength of the mortar specimens. Due to that the free water in the hydration reaction is not sufficient, the hydration products of the mortar specimens hydrated in the solution of water at later stage incorporate less chemical binding water. With the continuing of the hydration, the proportion of the main hydration products calcium silicate hydrate $(\mathrm{C}-\mathrm{S}-\mathrm{H})$ in the hydration products gradually increases and at the later stage the C-S-H products become dense and less impurity. Dry environment affects the formation of calcium hydroxide $(\mathrm{CH})$, and the interior pores in the mortar will not be filled. But in the dry environment, the structure of the hardness is formed. Calcium sulphoaluminate (ettringite, $\mathrm{AFt}$ ) in dry environment will change into a more stable mono-calcium sulphoaluminate (AFm). The mortar specimens curing in the solution of sodium nitrite are more relatively humid. In this case, C-S-H will form a thin sheet of low density structure to a great extent. $\mathrm{CH}$ is likely to continue to grow in the 
capillary hole, filling the pores to form larger crystals. AFt will not soon lose chemical binding water to form AFm. It illustrates that in the water environment, the section of the mortar specimens are not dense but the compressive strength are larger, while in the solution of sodium nitrite, section of the mortar specimens are dense but the compressive strength are lower. On the other hand, hydration of cementitious material continuously absorb water, which produces continuous sodium nitrite precipitation from solution. And the sodium nitrite deliquesces easily and thus absorbing the surrounding moisture, which provides moisture for the later stage hydration of the specimens, but from a certain point of view, the water to cement ratio of the mortar is increased. Corresponding to the correlated formula of the water to binder ratio and strength, with the increase of water to cement ratio, the strength of the same ratio will decrease.

\section{Conclusions}

(1) The usage of sodium nitrite in low-temperature concrete has affected the formation of its internal hydration products and increases the production of sulphoaluminate at early stage, which leads to dense structure of cement mortar specimen curing at $5^{\circ} \mathrm{C}$ but with lower strength.

(2) With the increase of addition of fly ash, the influence of sodium nitrite environment on the strength development of the cement mortar specimen curing at $5^{\circ} \mathrm{C}$ tends to be strengthened.

\section{Acknowledgements}

The authors would like to express the appreciation for the financial support by Liaoning BaiQianWan Talents Program（NO.2013921034）.

\section{References}

[1] $\mathrm{Ng} \mathrm{K}$, Sun Y, Dai Q, et al. Investigation of internal frost damage in cementitious materials with micromechanics analysis, SEM imaging and ultrasonic wave scattering techniques[J]. Construction \& Building Materials, 2014, 50(2):478-485.

[2] Hanjari K Z, Utgenannt P, Lundgren K. Experimental study of the material and bond properties of frost-damaged concrete[J]. Cement \& Concrete Research, 2011, 41(3):244-254.

[3] Zaharieva R, Buyle-Bodin F, Wirquin E. Frost resistance of recycled aggregate concrete[J]. Cement \& Concrete Research, 2004, 34(10):1927-1932.

[4] Karagöl F, Demirboğa R, Kaygusuz M A, et al. The influence of calcium nitrate as antifreeze admixture on the compressive strength of concrete exposed to low temperatures[J]. Cold Regions Science \& Technology, 2013, 89(5):30-35.

[5] Zoran Bonić, Gordana Topličić Ćurčić, et al. Damage of Concrete and Reinforcement of Reinforced-Concrete Foundations Caused by Environmental Effects[J]. Procedia Engineering, 2015,117:411-418.

[6] Rey I D, Ayuso J, Galvín A P, et al. Analysis of chromium and sulphate origins in construction recycled materials based on leaching test results.[J]. Waste Management, 2015.

[7] Verganelaki A, Kilikoglou V, Karatasios I, et al. A biomimetic approach to strengthen and protect construction materials with a novel calcium-oxalate-silica nano-composite[J]. Construction \& Building Materials, 2014, 62(2):8-17.

[8] Liu Z, Sha A, Xing M, et al. Low temperature property and salt releasing characteristics of antifreeze asphalt concrete under static and dynamic conditions[J]. Cold Regions Science \& Technology, 2015, 114:9-14. 